\title{
ARTICLE
}

\section{PEP-19 modulates calcium binding to calmodulin by electrostatic steering}

Xu Wang ${ }^{1} \&$ John A. Putkey ${ }^{1}$

PEP-19 is a small protein that increases the rates of $\mathrm{Ca}^{2}+$ binding to the $\mathrm{C}$-domain of calmodulin (CaM) by an unknown mechanism. Although an IQ motif promotes binding to $\mathrm{CaM}$, an acidic sequence in PEP-19 is required to modulate $\mathrm{Ca}^{2}+$ binding and to sensitize HeLa cells to ATP-induced $\mathrm{Ca}^{2}+$ release. Here, we report the NMR solution structure of a complex between PEP-19 and the C-domain of apo CaM. The acidic sequence of PEP-19 associates between helices $\mathrm{E}$ and $\mathrm{F}$ of $\mathrm{CaM}$ via hydrophobic interactions. This allows the acidic side chains in PEP-19 to extend toward the solvent and form a negatively charged surface that resembles a catcher's mitt near $\mathrm{Ca}^{2+}$ binding loop III of CaM. The topology and gradients of negative electrostatic surface potential support a mechanism by which PEP-19 increases the rate of $\mathrm{Ca}^{2+}$ binding to the $\mathrm{C}$-domain of CaM by 'catching' and electrostatically steering $\mathrm{Ca}^{2}+$ to site III.

\footnotetext{
${ }^{1}$ Department of Biochemistry and Molecular Biology, McGovern Medical at UTHealth, 6431 Fannin, Houston, Texas 77030, USA. Correspondence and requests for materials should be addressed to J.A.P. (email: John.Putkey@uth.tmc.edu).
} 
C almodulin (CaM) is a ubiquitous $\mathrm{Ca}^{2}+$ sensor protein that is highly conserved and essential for the survival and function of all eukaryotic cells. CaM consists of globular $\mathrm{N}$ - and C-domains connected by a flexible linker that allows structural diversity in target protein recognition ${ }^{1-3}$. The C-domain of vertebrate $\mathrm{CaM}$ binds $\mathrm{Ca}^{2}+$ with slightly greater affinity $\left(K_{\mathrm{Ca} 50} \approx 2 \mu \mathrm{M}\right)$ than the $\mathrm{N}$-domain $\left(K_{\mathrm{Ca} 50} \approx 10 \mu \mathrm{M}\right)^{4-6}$, but the most striking difference is that the rates of $\mathrm{Ca}^{2}+$ association and dissociation at the $\mathrm{C}$-domain are at least 30- to 150-fold slower than for the $\mathrm{N}$-domain ${ }^{7-9}$. Thus, $\mathrm{Ca}^{2+}$ binding to the $\mathrm{C}$-domain is rate-limiting for $\mathrm{CaM}$ to attain the fully $\mathrm{Ca}^{2+}$-saturated state. Clearly, proteins that could potentially modulate or tune the $\mathrm{Ca}^{2+}$ binding properties of $\mathrm{CaM}$ would enhance its ability to sense diverse $\mathrm{Ca}^{2}+$ signals that vary greatly in amplitude and frequency. Our search for such regulators of CaM signalling led us to a small, intrinsically disordered protein called PEP-19.

PEP-19 has no known intrinsic activity other than binding selectively to the C-domain of $\mathrm{CaM}$ via an IQ motif (IQXXXR(GX)XXX). Although originally identified in the central nervous system ${ }^{10}$, PEP-19 mRNA is also found in human bladder, kidney, prostate, uterus, thyroid, cardiac and adrenal tissues. Consistent with its role as a regulator of CaM signalling or RCS protein, PEP-19 exerts broad effects on diverse cellular processes. For example, PEP-19 null mice show a dramatic reduction in long-term plasticity at synapses between granule cell parallel fibres and Purkinje cells ${ }^{11}$, as well as altered cardiac excitability ${ }^{12}$. Overexpression of PEP-19 in PC12 cells increases neurite outgrowth ${ }^{13}$, and premature neuronal differentiation is seen in transgenic mice with three copies of the PEP-19 gene ${ }^{14}$. In addition, PEP-19 has anti-apoptotic activity when expressed in PC12 and HEK293T cells ${ }^{15,16}$, and it provides protection against $\mathrm{Ca}^{2+}$ overload in cortical neurons ${ }^{16}$. Finally, PEP-19 sensitizes HeLa cells to ATP-dependent $\mathrm{Ca}^{2+}$ release ${ }^{17}$.

We discovered that PEP-19 has the remarkable ability to increase both the $\mathrm{Ca}^{2}+k_{\text {on }}$ and $k_{\text {off }}$ rates at the C-domain of CaM up to 40 -fold with little effect on $\mathrm{Ca}^{2}+$ binding affinity ${ }^{9}$, and that this property is dependent on an acidic sequence located adjacent to the IQ motif. Moreover, the acidic sequence is required for PEP-19 to sensitize HeLa cells to ATP-dependent $\mathrm{Ca}^{2}+$ release. Deleting or mutating the acidic sequence by, for example, converting Pro37 to Gly (PEP(P37G)) does not prevent PEP-19 from binding to CaM, but greatly decreases its ability to both modulate $\mathrm{Ca}^{2+}$ binding to $\mathrm{C}$-domain of $\mathrm{CaM}$ and to sensitize HeLa cells to ATP-induced $\mathrm{Ca}^{2+}$ release ${ }^{17}$. This demonstrates that simply binding to CaM does not account for all the biological activities of PEP-19, and that tuning $\mathrm{Ca}^{2+}$ binding to $\mathrm{CaM}$ via the cooperative properties of its acidic sequence and IQ motif is an important mechanism by which PEP-19 impacts at least some CaM signalling pathways.

The ability of PEP-19 to increase the rate-limiting association of $\mathrm{Ca}^{2+}$ with the C-domain of apo CaM has the potential to regulate the temporal binding of $\mathrm{CaM}$ to a wide spectrum of $\mathrm{Ca}^{2+}$. dependent target proteins. This led us to determine the NMR solution structure of the PEP-19:apo C-CaM complex to reveal the molecular mechanism by which PEP-19 modulates the rate of $\mathrm{Ca}^{2+}$ binding to C-CaM. The structure, coupled with analysis the mutant $\mathrm{PEP}(\mathrm{P} 37 \mathrm{G})$, demonstrate the importance of properly orienting the acidic residues in PEP-19 within the complex to increase the negative electrostatic surface potential (ESP), and electrostatically steer $\mathrm{Ca}^{2+}$ to site III in the C-domain of CaM.

\section{Results}

Use of C-CaM to study interactions between PEP-19 and CaM. We focused our structural analysis on interactions between PEP-19 and apo CaM since increasing the rate-limiting association of $\mathrm{Ca}^{2+}$ with the $\mathrm{C}$-domain of $\mathrm{CaM}$ has the potential to increase its rate of association with other $\mathrm{Ca}^{2}+$-dependent target proteins. We used the isolated C-domain of CaM (C-CaM) since we showed previously that PEP-19 binds preferentially to the C-domain ${ }^{6,18}$, and that PEP-19 has the same effect on the $\mathrm{Ca}^{2+}$ binding properties of both intact $\mathrm{CaM}$ and $\mathrm{C}-\mathrm{CaM}^{19}$. The extent of preferential binding of PEP-19 to the C-domain of apo $\mathrm{CaM}$ is emphasized in Supplementary Fig. 1a. PEP-19 has essentially no effect on backbone amide chemical shifts in the $\mathrm{N}$-domain of apo $\mathrm{CaM}$ with an average change of only 0.007 p.p.m. for residues $3-73$. In contrast, the average chemical shift perturbation across residues $81-148$ in the C-domain of $\mathrm{CaM}$ is 0.27 p.p.m. Supplementary Fig. 1b,c show that the PEP-19 has the essentially same effects on the pattern and magnitude of backbone amide chemical shifts in both intact apo $\mathrm{CaM}$ and apo C-CaM, which suggests that the conformational change is also the same. Moreover, these changes are maximal at 1:1 molar ratio of PEP-19 to CaM or C-CaM. These data demonstrate that $\mathrm{C}-\mathrm{CaM}$ is a valid structural model for the interaction between PEP-19 and CaM.

Effects of apo C-CaM on the global structure of PEP-19. Figure 1a shows that association with apo C-CaM has no effect on amide chemical shifts of residues $1-29$ in ${ }^{15} \mathrm{~N}$-labelled PEP-19, but large changes are observed for residues 30-58, which span both the acidic sequence and core IQ motif (see full spectra in Supplementary Fig. 2). The open bar in Fig. 1a indicates that Glu38 to Ala58 in PEP-19 are predicted to adopt $\alpha$-helical
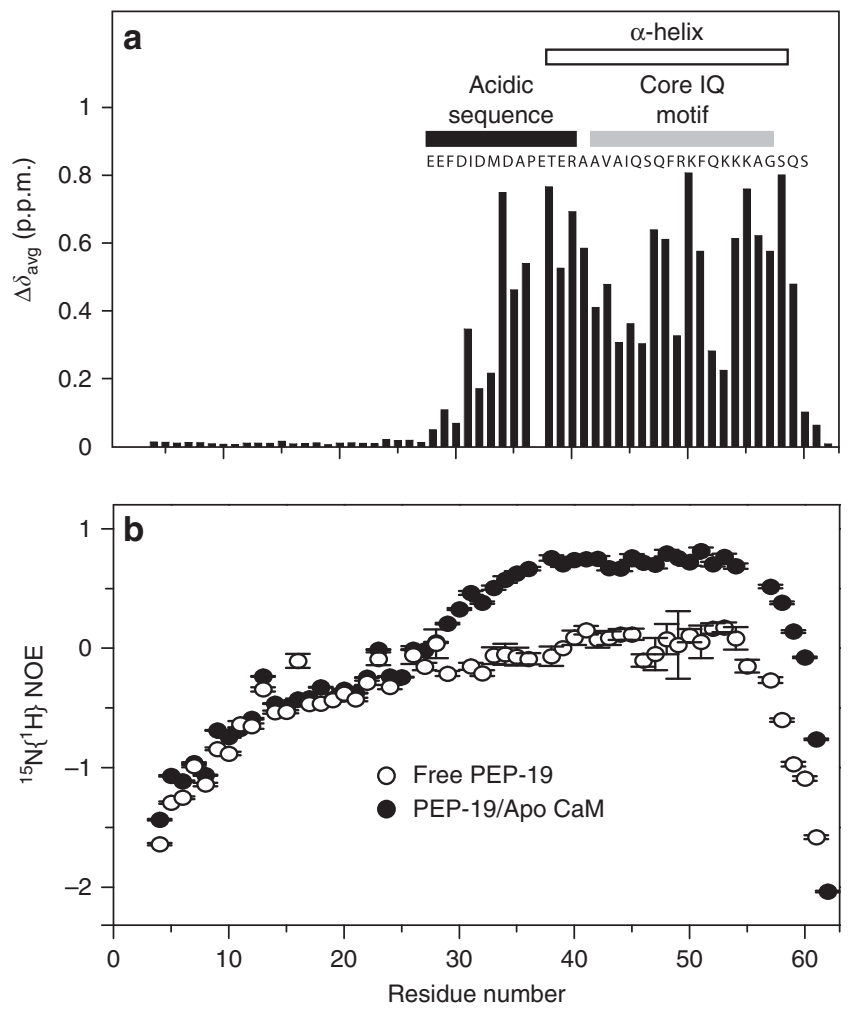

Figure 1 | Structural transitions in PEP-19 on binding to apo C-CaM are restricted to its acidic sequence and the core IQ motif. (a) Backbone amide chemical shift changes calculated using equation (1) in ${ }^{15} \mathrm{~N}$-labelled PEP-19 on binding to apo C-CaM. (b) Steady-state ${ }^{15} \mathrm{~N}\left\{{ }^{1} \mathrm{H}\right\}$ NOEs of ${ }^{15} \mathrm{~N}$ free PEP-19 (open circles) and ${ }^{15} \mathrm{~N}$ PEP-19 bound to apo C-CaM (closed circles). The ${ }^{15} \mathrm{~N}\left\{{ }^{1} \mathrm{H}\right\}$ NOE values and the uncertainty of NOE values (error bars) were determined as described in the 'Methods' section. 
secondary structure on binding to apo C-CaM based on the chemical shift index (CSI). Although binding to apo C-CaM causes large amide chemical shift changes for residues 30-36 in the acidic sequence of PEP-19, the CSI assigns this region to neither $\alpha$-helix nor $\beta$-sheet secondary structure. Heteronuclear ${ }^{15} \mathrm{~N}\left\{{ }^{1} \mathrm{H}\right\}$ nuclear Overhauser effects (NOEs) for free PEP-19 shown in Fig. $1 \mathrm{~b}$ are predominantly negative, which is consistent with a highly flexible, intrinsically disordered protein. The ${ }^{15} \mathrm{~N}\left\{{ }^{1} \mathrm{H}\right\}$ NOE values for residues Phe30-Ala36 in PEP-19 bound to apo $\mathrm{C}-\mathrm{CaM}$, show a gradual increase from 0 to 0.8 , then the ${ }^{15} \mathrm{~N}\left\{{ }^{1} \mathrm{H}\right\}$ NOE values remain high for residues Glu38-Ala58, which is consistent with a well-ordered $\alpha$-helix.

Structure determination of the PEP-19:apo C-CaM complex. Over $99 \%$ of side chain protons were assigned for the PEP-19:apo C-CaM complex. Table 1 shows restraints used for structure calculations as well as structural statistics for an ensemble of the 20 lowest energy structures. The restraints included 1,926 NOE distance restraints, 98 predicted hydrogen bond distance

\section{Table 1 | Experimental restraints and structural statistics for an ensemble of 20 NMR structures for the PEP-19:apo C-CaM complex.}

NMR distance, RDC and dihedral constraints

Distance restraints

Total NOEs

C-CaM

Intraresidue $(|i-j|=0)$

Sequential $(|i-j|=1) \quad 280$

Medium range $(1<|i-j|<5) \quad 213$

Long range $(|i-j| \geq 5)$

PEP-19 (Phe30-Ser62)

Intraresidue $(|i-j|=0)$

Sequential $(|i-j|=1) \quad 120$

Medium range $(1<|i-j|<5)$

Long range $(|i-j| \geq 5)$

Intermolecular

Ambiguous

Total predicted hydrogen bonds

C-CaM

PEP-19 (Phe30-Ser62)

Total RDC restraints $(\mathrm{H}-\mathrm{N})$

C-CaM

PEP-19

Total dihedral angle restraints 162

C-CaM

PEP-19 (Phe30-Ser62)

Structural statistics

Violations

Distance constraints $(\AA)$

Dihedral angle constraints $\left(^{\circ}\right)$

RDC constraints $(\mathrm{Hz})$

Max. distance constraint violation $(\AA)$

Max. dihedral constraint violation $\left(^{\circ}\right)$

Deviations from idealized geometry

Bond lengths $(\AA)$

Bond angles $\left({ }^{\circ}\right)$

Impropers $\left(^{\circ}\right)$

Average pairwise RMSD $(\AA)$

C-CaM (Glu81-Ala128 and GIn135-Thr146)

Backbone

All heavy atoms

PEP-19 (Phe30-Lys57)

Backbone

All heavy atoms

$0.53 \pm 0.12$

$1.53 \pm 0.15$ restraints, $162 \varphi$ and $\Psi$ angles from TALOS and 60 backbone $\mathrm{H}-\mathrm{N}$ residual dipolar couplings (RDCs). Figure $2 \mathrm{a}$ shows a stereo view of the 20 lowest energy structures. Consistent with the data in Fig. 1a,b, residues 1-29 in PEP-19 remain disordered when bound to apo C-CaM, and show no detectable medium or long range intramolecular or intermolecular NOEs. Figure $2 \mathrm{~b}$ shows the minimized average structure of the ensemble, excluding the disordered $\mathrm{N}$-terminal region in PEP-19. Apo $\mathrm{C}-\mathrm{CaM}$ is shown in dark blue, the acidic sequence is in red and the IQ motif of PEP-19 is in light blue.

Structural features of apo C-CaM bound to PEP-19. On the basis of the CSI and TALOS, secondary structural elements in apo C-CaM bound to PEP-19 include helix E (aa 81-92), helix F (aa 102-111), helix G (aa 118-128), helix H (aa 138-146), $\beta$-strand III (aa 99-101) and $\beta$-strand IV (aa 135-137). Residues 93-104 and 129-140 form $\mathrm{Ca}^{2+}$ binding loops III and IV, respectively. The global backbone conformation of apo $\mathrm{C}-\mathrm{CaM}$ bound to PEP-19 conforms to a semi-open state, with a shallow hydrophobic groove to accommodate the helical IQ motif of PEP-19. Pairwise structural alignments show that the closest structural relatives to apo C-CaM bound to PEP-19 are structures of semi-open CaM bound to other IQ motif peptides and proteins. Supplementary Fig. 3 shows an overlay of backbone structures for C-CaM bound to intact PEP-19 and those of C-CaM derived from the crystal structures of CaM bound to the IQ motif in the cytoplasmic domain of the voltage-gated sodium channel $\mathrm{Na}_{\mathrm{V}} 1.5$ (ref. 20) or the IQ region of myosin $\mathrm{V}^{21}$. The structures are shown without PEP-19 or the IQ peptides to emphasize spatial similarity of the 4 helices in C-CaM. Supplementary Table 1 compares helical angles for $\mathrm{Ca}^{2+}$ binding sites III and IV in $\mathrm{Ca}^{2+}$ and apo CaM versus the semi-open conformation of apo CaM bound to PEP-19 or the IQ peptide from the $\mathrm{Na}_{\mathrm{V}} 1.5$ channel $^{20}$. Interestingly, the semi-open conformation in these complexes is largely due to a conformational change in site III since the helical angles of site III in apo CaM bound to either PEP-19 or the IQ peptide from $\mathrm{Na}_{V} 1.5$ are essentially identical to free $\mathrm{Ca}^{2}+$ bound CaM.

Two experiments argue against the semi-open conformation of apo C-CaM as the primary molecular mechanism by which PEP-19 increases the rate of $\mathrm{Ca}^{2+}$ association. First, a peptide encompassing the IQ motif of PEP-19, but lacking the acidic sequence, does not increase the $\mathrm{Ca}^{2}+k_{\text {on }}$ (ref. 6). Second, Supplementary Fig. 4 shows that the IQ peptide from the voltage-gated sodium channel $\mathrm{Na}_{\mathrm{V}} 1.5$ (aa 1,901-1,927), which lacks an acidic sequence but clearly induces a semi-open conformation in the $\mathrm{C}$-domain of $\mathrm{CaM}^{22}$, has little effect on the rate of $\mathrm{Ca}^{2+}$ association.

Although the helical angle for site III of apo CaM bound to PEP-19 is more similar to $\mathrm{Ca}^{2}+\mathrm{CaM}$, the backbone conformation and side chain orientations for residues 93-104 in the $\mathrm{Ca}^{2+}$ binding loop III are much more similar to free apo CaM. The conformation of $\mathrm{Ca}^{2+}$ binding loop III in the PEP-19:apo C-CaM complex is fairly well defined with 85 medium and long range NOEs, and appears to be stabilized by a network of hydrogen bonds involving the side chain oxygens of Asp93 and backbone amides of residues 94-99 (also see the 'Discussion' section). In contrast, only 18 medium and long range NOEs are observed in loop IV. This is consistent with amide line broadening observed for residues 129-134 due to chemical exchange, which was also seen for apo CaM bound to the IQ motif peptide of $\mathrm{Na}_{\mathrm{V}} 1.5$ (ref. 20).

RDC, residual dipolar couplings; RMSD, root-mean-square deviation.

Interaction between C-CaM and the helical portion of PEP-19. PEP-19 binds to C-CaM in a parallel orientation with the 

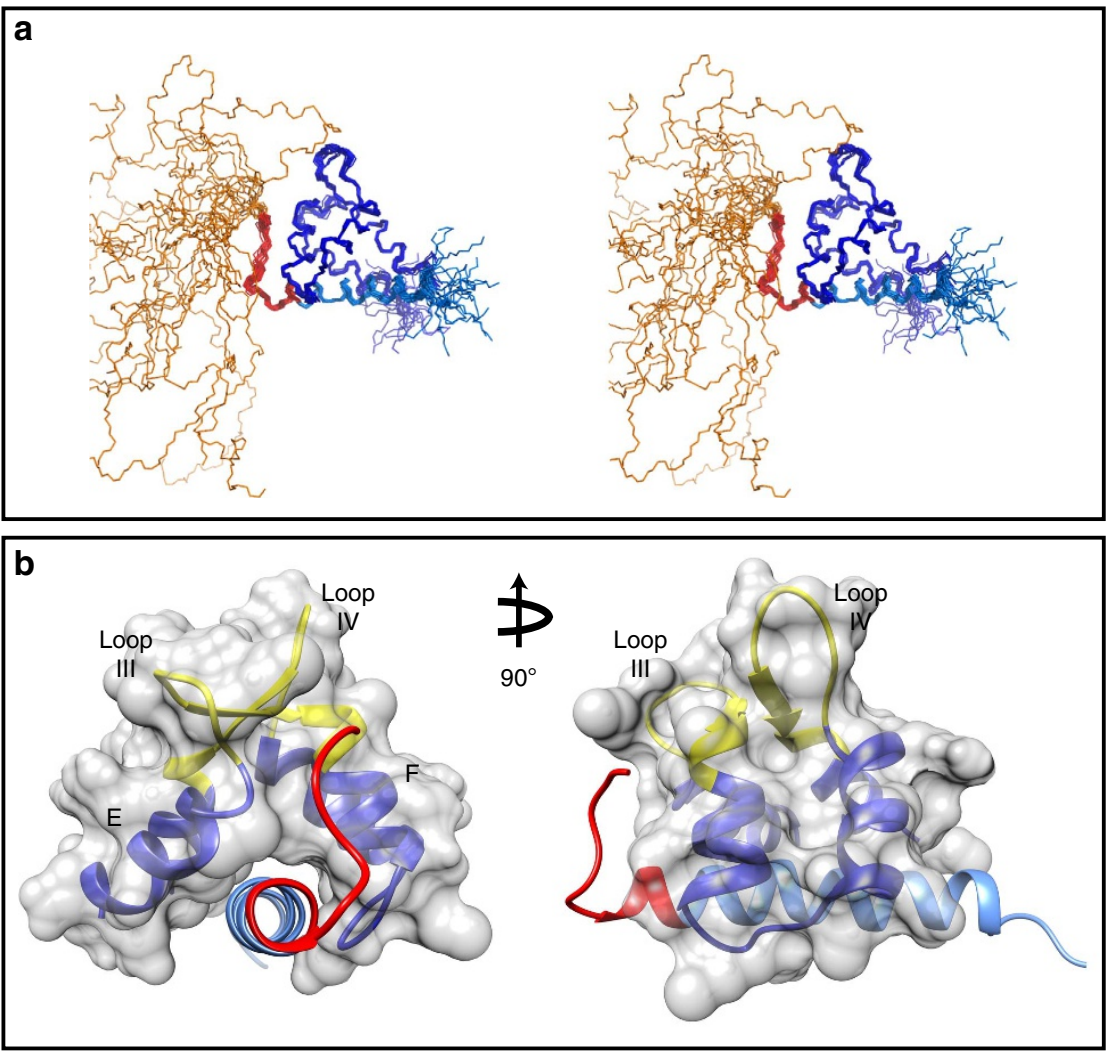

Figure 2 | Three-dimensional solution structure of the PEP-19:apo C-CaM complex. (a) An stereo representation of an overlay of all backbone atoms for the final ensemble of 20 lowest energy conformers. Apo C-CaM is shown in dark blue. The disordered N terminus (aa 1-29), acidic sequence (aa 30-40) and IQ motif (aa 41-62) are shown in gold, red and light blue, respectively. (b) Ribbon representations for the structured regions of average minimized structure excluding the disordered N-terminal region of PEP-19. The colour scheme is the same as in a. Roman numerals III and IV indicate the $\mathrm{Ca}^{2}+$ binding loops of EF-hands III and IV, respectively, which are shown in yellow. All other figures also use the averaged minimized structure for the ensemble.

$\mathrm{N}$-terminal residues interacting with helices $\mathrm{E}$ and $\mathrm{F}$ of $\mathrm{Ca}^{2+}$ binding site III, while the C-terminal residues interact with helices $\mathrm{G}$ and $\mathrm{H}$ in $\mathrm{Ca}^{2}+$ binding site IV. The average total buried surface area is $2,157 \AA^{2}$ for the five lowest energy conformers in the ensemble. Figure $3 a$ summarizes residues in the helical portion of PEP-19 that form intermolecular NOEs with residues in C-CaM. The majority of NOEs arise from hydrophobic interactions involving non-polar atoms in Thr39, Ala42, Ala43, Ala45, Ile46, Gln47, Phe50 and Phe53 in PEP-19. Figure $3 \mathrm{~b}$ shows that these residues (red) are predominantly located on one surface of the helical segment in PEP-19. They are deeply buried in the complex, with $89 \%$ of their side chain surfaces excluded from solvent, which allows them to form hydrophobic interactions primarily with Phe89, Phe92, Val108, Met109, Met124, Met144 and Met145 in C-CaM, which line the shallow hydrophobic groove (see grey side chains in Fig. 3b). In addition to these hydrophobic interactions, electrostatic interactions include hydrogen bonds between Gln 47 in the IQ dipeptide of PEP-19 and backbone atoms of Ile112 and Glu114 in the linker between helices $\mathrm{F}$ and $\mathrm{G}$ in apo $\mathrm{C}-\mathrm{CaM}$, as well as ionic bonds between the side chains of Arg51 in PEP-19 and Glu114 in C-CaM.

The importance of these residues for binding to $\mathrm{CaM}$ is supported by a study using synthetic peptides that span residues 36-60 in the IQ motif of PEP-19 (ref. 23). Peptides with Ile46 and Gln47 changed to Gly, as well as the single mutations A42D, F50G, R51K, K56A and K57A all inhibited their ability to inhibit CaM activation of nNOS at low $\mathrm{Ca}^{2+}$. Similarly, introducing the mutations Q47N and S48T effectively prevented intact PEP-19 from binding to $\mathrm{CaM}$, and from conferring resistance to $\mathrm{Ca}^{2+}$-mediated cytotoxicity ${ }^{16}$.

Interactions between C-CaM and the acidic loop in PEP-19. Figures $2 \mathrm{~b}$ and $4 \mathrm{a}$ show that the acidic sequence in PEP-19 (aa 30-40 in red) associates with $\mathrm{Ca}^{2}+$ binding site III. Residues 30-36 in PEP-19 form an extended coil structure that runs between helices $\mathrm{E}$ and $\mathrm{F}$ of $\mathrm{Ca}^{2+}$ binding site III. The coil segment terminates at Pro37, and residues 38-40 of the acidic sequence form the $\mathrm{N}$ terminus of the $\alpha$-helix in PEP-19. The buried surface between the acidic sequence and C-CaM is $725 \AA^{2}$, which is $30 \%$ of the total buried surface area in the complex.

Figure 4a shows that the side chains of Phe30, Ile32 and Met34 of PEP-19 form a hydrophobic plug that inserts between helices $\mathrm{E}$ and $\mathrm{F}$ of $\mathrm{Ca}^{2}+$ binding site III to stabilize the extended coil segment of PEP-19. The side chains of these three residues account for $89 \%$ of the buried surface area in the acidic sequence of PEP-19. A total of 39 intermolecular NOEs are observed between C-CaM and the side chains of Phe30, Ile32 and Met34 in PEP-19. This extensive network of NOEs is illustrated in Fig. 4b, which shows selected planes acquired from $\mathrm{F}_{1}$-filtered, $\mathrm{F}_{3}$-edited NOESY-HSQC using ${ }^{13} \mathrm{C},{ }^{15} \mathrm{~N}$ PEP-19 bound to unlabelled C-CaM. The H $\delta 1$ of Ile32 in PEP-19 shows intermolecular NOEs to Val91, Phe92, Glu104 and His107 in C-CaM. The He of Met34 in PEP-19 shows intermolecular NOEs to Phe92, His107, Val108, Asn111 and Leu112 in C-CaM (see grey side chains in Fig. 4a). Most of these residues in C-CaM also form intermolecular NOEs with residues in the helical portion of PEP-19, especially Ile46 of 

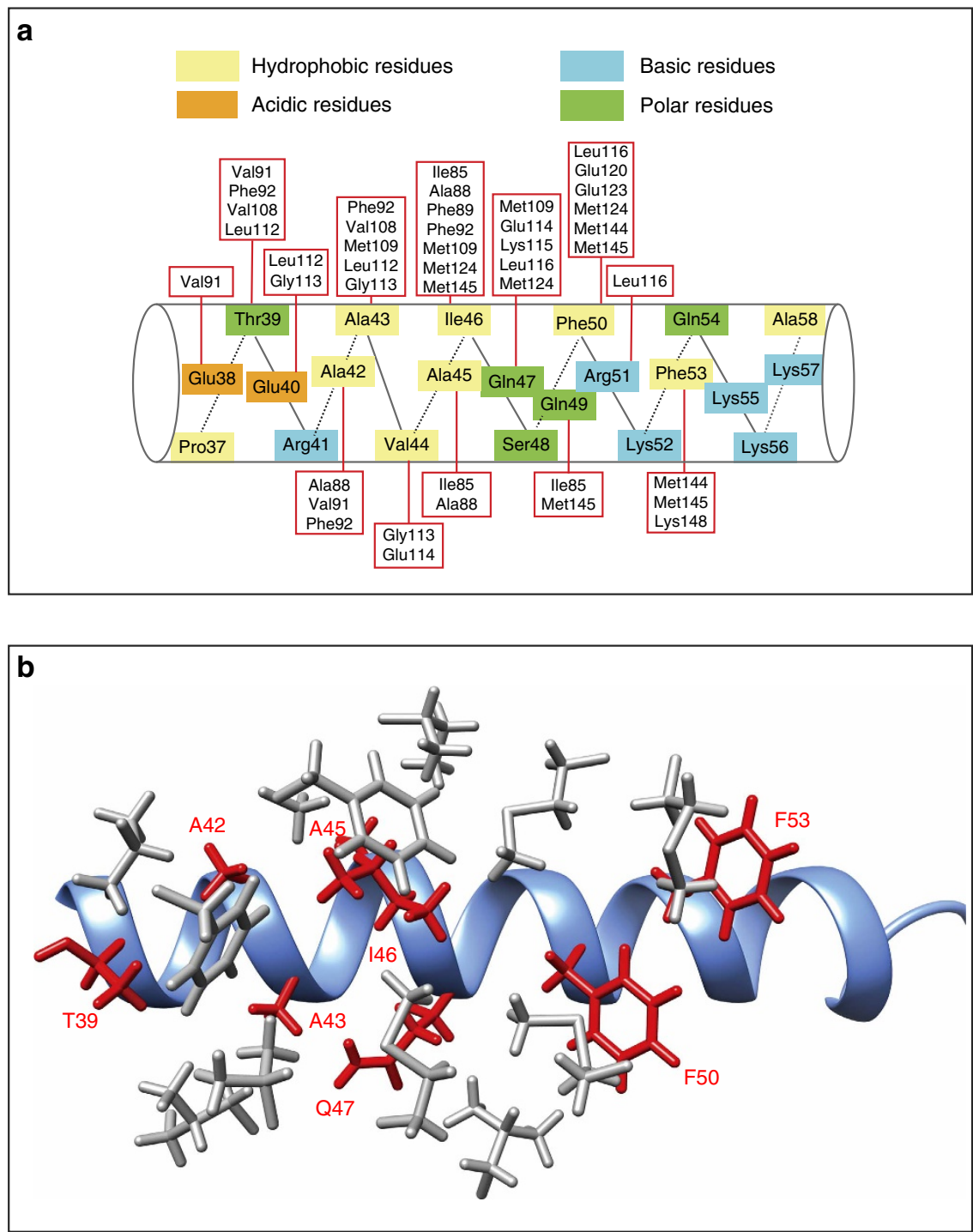

Figure 3 | Interactions between the helical portion of PEP-19 and apo C-CaM. (a) Intermolecular NOEs observed between residues in the helical segment of PEP-19 and residues in apo C-CaM. (b) A ribbon diagram of the helical portion of PEP-19 (light blue) with side chains (red) that form hydrophobic interactions with residues in apo C-CaM (grey).

the IQ dipeptide. This network of hydrophobic interactions may provide allosteric communication between the acidic loop and helical region of PEP-19 bound to apo C-CaM.

PEP-19 generates negative ESP near $\mathrm{Ca}^{2+}$ binding loop III. Figure $5 \mathrm{a}, \mathrm{b}$ focus on $\mathrm{Ca}^{2}+$ binding site III in free apo C-CaM and the PEP-19:apo C-CaM complex. As mentioned above, the conformation of loop III is similar in both structures. While the angle formed by helices $\mathrm{E}$ and $\mathrm{F}$ is quite different between the structures, this alone does not account for the altered $\mathrm{Ca}^{2}+$ binding kinetics induced by PEP-19. This led us to evaluate the effect of PEP-19 on ESP. Figure 5a shows that the side chains of Asp35 and Glu40 in the acidic sequence of PEP-19 extend away from $\mathrm{Ca}^{2+}$ binding loop III. However, the side chains of Asp31, Asp33 and Glu38 lie along the surface of the acidic sequence that opposes helix E and the first three residues in loop III of C-CaM (aa 93-95). Figure 5c shows that the acidic residues in PEP-19 combine with Glu84, Glu87, Asp93 and Asp95 in C-CaM to form a large surface with significant negative ESP. This contrasts with the more neutral ESP shown for free apo CaM in Fig. 5d. A view of loop III from another angle in Supplementary Fig. 5 shows a foci of negative ESP is also formed from the side chains of Asp93 and Glu104.

Effects of PEP(P37G) mutation on the acidic sequence. We showed previously that replacing Pro37 with Gly (PEP(P37G)) greatly inhibits the ability of PEP-19 modulate $\mathrm{Ca}^{2}+$ binding to $\mathrm{CaM}$, and to sensitize HeLa cells to ATP-dependent $\mathrm{Ca}^{2+}$ release $^{17}$. Figure 4a shows that Pro37 terminates the helical segment of PEP-19, and intramolecular NOEs show that Pro37 and Ala36 interact with neighbouring residues to stabilize the transition between helical and coiled segments in PEP-19. Thus, a plausible hypothesis is that conversion of Pro37 to Gly confers a high degree of flexibility that inhibits residues 30-36 from properly interacting with CaM. To test this hypothesis, we used chemical shift perturbation mapping and paramagnetic relaxation enhancement (PRE) to determine the effects of mutation of Pro37 on the structure and position of the acidic sequence.

Supplementary Fig. 6a shows that conversion of Pro37 to Gly causes relatively small amide chemical shift perturbations in free 

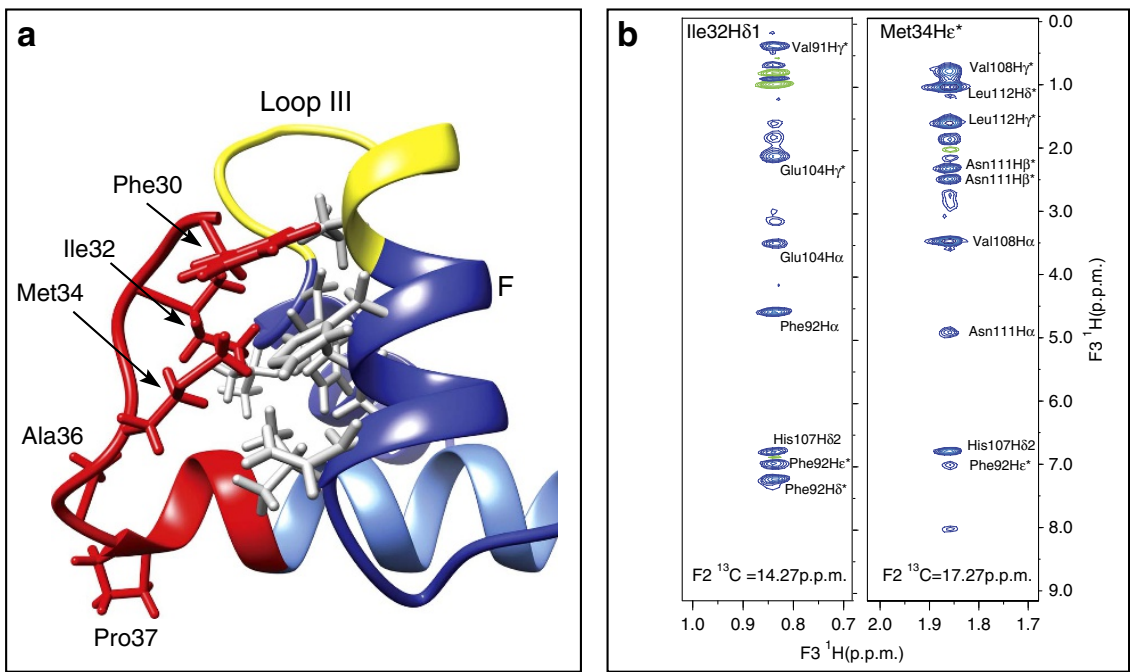

Figure 4 | Interactions between the acidic sequence of PEP-19 and helices E and F of $\mathbf{C a}^{2+}$ binding site III in apo C-CaM. The acidic sequence is shown in red, helices $\mathrm{E}$ and $\mathrm{F}$ in C-CaM are shown in dark blue, and $\mathrm{Ca}^{2+}$ binding loop III is in yellow. (a) Phe30, lle32 and Met34 in the extended coil region in PEP-19 form hydrophobic interactions with residues in C-CaM (grey) that are at the interface between helices E and F in Ca ${ }^{2+}$ binding site III. (b) Selected planes acquired from $\mathrm{F}_{1}$-filtered, $\mathrm{F}_{3}$-edited NOESY-HSQC using ${ }^{13} \mathrm{C},{ }^{15} \mathrm{~N}$ PEP-19 bound to unlabelled $\mathrm{C}$-CaM. The planes highlight numerous intermolecular NOEs from $\mathrm{H} \delta 1$ of $l l e 32$ and $\mathrm{H} \varepsilon$ of Met34 in PEP-19 to residues in C-CaM.
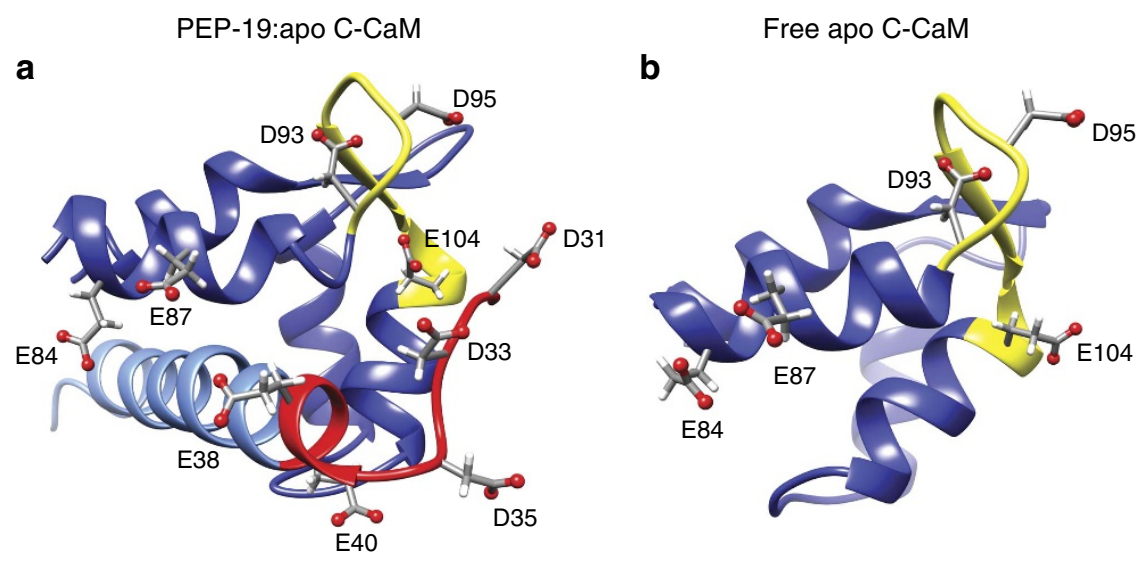

c

d

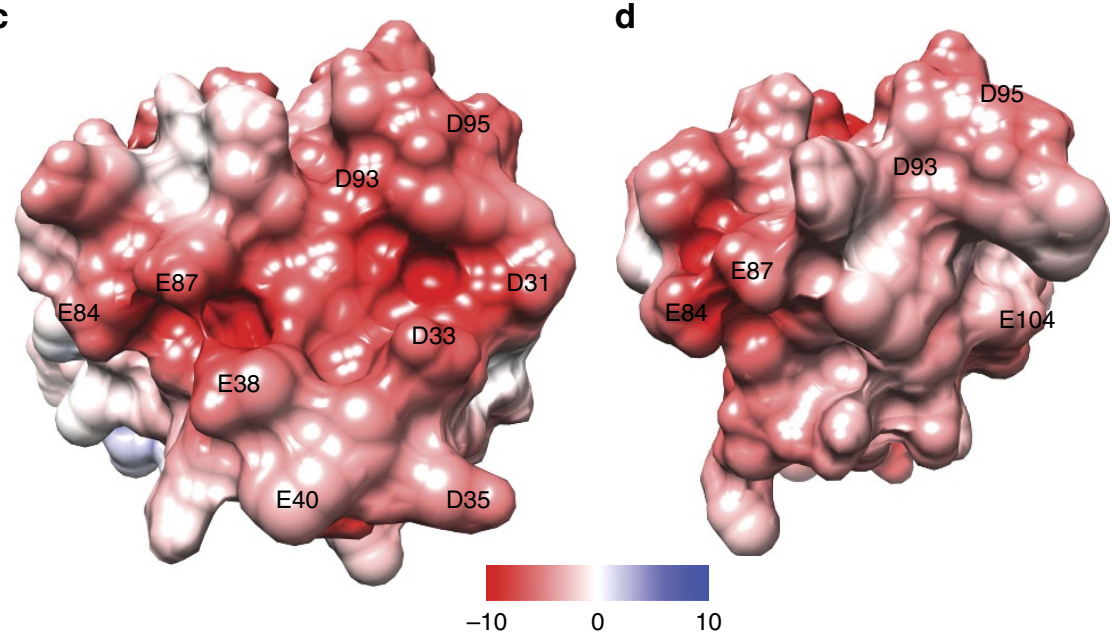

Figure 5 | The acidic sequence of PEP-19 greatly increases the negative ESP near $\mathbf{C a}^{2}+$ binding site III of apo C-CaM. (a,b) Ribbon diagrams for the PEP-19:apo C-CaM complex and free C-CaM, respectively. Dark blue is C-CaM, yellow is $\mathrm{Ca}^{2+}$ binding loop III, red and light blue are the acidic sequence and core IQ motif in PEP-19, respectively. (c,d) Solvent excluded surfaces that are coloured based on ESP. 
PEP-19 that are restricted to residues near Pro37. In contrast, Supplementary Fig. $6 \mathrm{~b}$ shows that when bound to apo C-CaM, large chemical shift differences between PEP-19 and PEP(P37G) extend the length of the acidic sequence from Asp31 to Glu40. In addition, Supplementary Fig. 7a shows significantly reduced amide ${ }^{1} \mathrm{H}$ chemical shift dispersion for Asp31 to Glu40 in PEP(P37G) versus PEP-19 when bound to C-CaM, which suggests that the mutation destabilizes the acidic sequence. This is consistent with Supplementary Fig. 7b, which shows that residues $30-40$ in $\mathrm{PEP}(\mathrm{P} 37 \mathrm{G})$ bound to apo $\mathrm{C}-\mathrm{CaM}$ have the greatest decrease in ${ }^{15} \mathrm{~N}\left\{{ }^{1} \mathrm{H}\right\}$ NOEs relative to the native complex.

We next used PRE to determine if mutation of Pro37 to Gly in PEP-19 increases the distance between the acidic sequence and apo C-CaM. As described in the 'Methods' section, Asp31 in both PEP-19 and PEP(P37G) was converted to Cys as a site for covalent modification with PROXYL to yield spin-labelled PEP-19SL and PEP(P37G)SL, respectively. The PRE effect was measured as the normalized cross-peak intensity ratio $\left(I_{\mathrm{ox}} / I_{\text {red }}\right)$ of each amide in the oxidized and reduced states. The grey bars in Fig. 6a show the PRE effect on backbone amides in ${ }^{15} \mathrm{~N}$-labelled apo C-CaM bound to PEP-19SL. Similar to Battiste and Wagner ${ }^{24}$, a PRE effect was indicated by $I_{\text {ox }} / I_{\text {red }}$ ratios of $<0.85$ (see dashed horizontal line). The pattern of amide $I_{\text {ox }} / I_{\text {red }}$ ratios correlates well with the location of the spin label on residue 31 near $\mathrm{Ca}^{2}+$ binding loop III. Residues with amide $I_{\text {ox }} / I_{\text {red }}$ ratios $<0.2$, or that are broadened beyond detection by the oxidized spin label, include Asp93, Lys94 and Asp95, which are the first three residues in $\mathrm{Ca}^{2+}$ binding loop III, and Ile100 through Val108, which form $\beta$-strand III and extend into helix F. The $I_{\text {ox }} / I_{\text {red }}$ ratios of $<0.5$ are seen for Gly96 to Tyr99 in loop III. A significant PRE effect is also seen for Gln135 and Val136, which is consistent with the location of these two residues in a short beta strand in site IV that forms a beta sheet with residues in site III.

The coloured vertical lines in Fig. 6a show differences in $I_{\mathrm{ox}} / I_{\text {red }}$ for ${ }^{15} \mathrm{~N}$-labelled apo C-CaM when bound to PEP(P37G)SL versus PEP-19SL. A red line indicates that the distance between the corresponding backbone amide in C-CaM and the spin label bound to Cys31 is increased by mutation of Pro37 to Gly. Conversely, a blue line indicates a decreased distance. Large increases in $I_{\text {ox }} / I_{\text {red }}$ ratios are seen for residues in $\mathrm{Ca}^{2+}$ binding loop III, helix F and $\beta$-strand IV when apo C-CaM is bound to PEP(P37G)SL versus PEP-19SL. Figure 6b shows the position of these amide protons in the solution structure of the PEP-19:apo C-CaM complex. Taken together, these data demonstrate that conversion of Pro37 to Gly destabilizes the interaction between the acidic sequence and apo C-CaM, to increase the average distance between the acidic sequence and $\mathrm{Ca}^{2}+$ binding site III, thus altering the orientation of the acidic side chains in PEP-19 relative to $\mathrm{C}-\mathrm{CaM}$, and likely affecting the negative ESP near $\mathrm{Ca}^{2}+$ binding site III.

\section{Discussion}

We report here the first structure of a complex between apo $\mathrm{CaM}$ and a protein that regulates the activity of $\mathrm{CaM}$, instead of a target protein that is regulated by CaM. Our goal was to identify molecular mechanisms by which PEP-19 modulates $\mathrm{Ca}^{2}+$ binding to CaM. We focused on the apo state since increasing the rate of $\mathrm{Ca}^{2}+$ binding to apo CaM by PEP-19 has the potential to regulate the temporal binding of $\mathrm{CaM}$ to a wide spectrum of $\mathrm{Ca}^{2+}$-dependent target proteins. Structural features of the acidic sequence of PEP-19 were of special interests since it is necessary to both modulate $\mathrm{Ca}^{2+}$ binding to CaM and to sensitize HeLa cells to ATP-dependent $\mathrm{Ca}^{2+}$ release ${ }^{17}$.
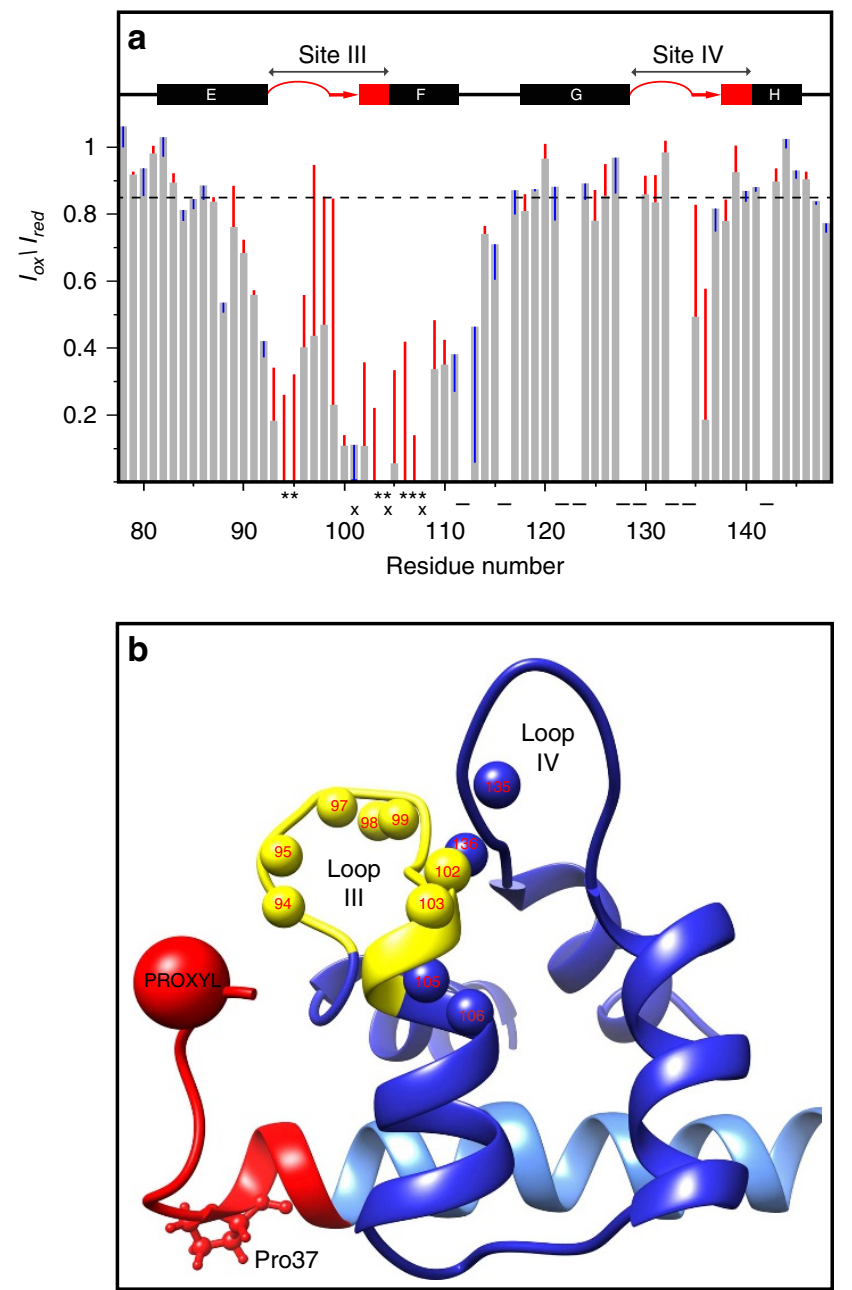

Figure 6 | Mutation of Pro37 to Gly in PEP-19 increases the distance between the acidic sequence and $\mathrm{Ca}^{2+}$ binding site III in apo $\mathrm{C}$-CaM. Asp31 in PEP-19 and PEP(P37G) was mutated to Cys and spin labelled for PRE analysis as described in the methods. The grey bars in (a) the normalized amide $I_{\mathrm{ox}} / I_{\text {red }}$ intensity ratios derived from ${ }^{1} \mathrm{H},{ }^{15} \mathrm{~N} \mathrm{HSQC}$ spectrum of apo C-CaM when bound to PEP-19(SL). The red and blue vertical lines indicate an increase or decrease, respectively, in $I_{\mathrm{ox}} / I_{\text {red }}$ due to mutation of Pro37 to Gly. The $I_{\text {ox }} / I_{\text {red }}$ could not be calculated for residues indicated by $(-)$ due to spectral overlap. Amide cross peaks for residue indicated by $\left({ }^{\star}\right)$ are line broadened beyond detection when $\mathrm{C}-\mathrm{CaM}$ is bound to PEP-19(SL), while those indicated by $(x)$ are line broadened beyond detection when bound to PEP(P37G)SL. (b) The location of amides (small balls) for residues in apo C-CaM that show the greatest increase in distance from the PROXYL probe with an increase in $I_{\text {ox }} / I_{\text {red }}$ of greater than 0.2 due to mutation of Pro37 to Gly. Calcium binding loop III is shown in yellow.

First, this is fuzzy complex ${ }^{25}$ since residues $1-29$ in PEP-19 remain disordered when bound to apo C-CaM. Although this disordered sequence is not required to modulate $\mathrm{Ca}^{2}+$ binding to $\mathrm{CaM}^{6}$, it may interact with other cellular proteins since residues 10-20 have a high propensity to form a $\beta$-turn based on analysis with ProtScale (http://web.expasy.org/protscale/). Second, the IQ motif (residues 38-58) adopts a regular $\alpha$-helix that lies along the shallow hydrophobic groove in semi-open apo C-CaM. Finally, and most significantly, residues $30-37$ of the acidic sequence in PEP-19 adopt an extended coil that associates with helices $\mathrm{E}$ and $\mathrm{F}$ in $\mathrm{Ca}^{2+}$ binding site III of CaM primarily via a hydrophobic plug formed from Phe30, Ile32 and Met34 in PEP-19, which allows the acidic residues to extend toward the solvent. 
To gain mechanistic insights from the structure, it is important to discuss the characteristics of cooperative $\mathrm{Ca}^{2+}$ binding to sites III and IV in CaM. Structural dynamics at low $\mathrm{Ca}^{2}+$ levels support the idea that the first $\mathrm{Ca}^{2}+$ binds preferentially to site IV, but with rapid $k_{\text {on }}$ and $k_{\text {off }}$ rates ${ }^{26}$. Since the overall rate of association of two $\mathrm{Ca}^{2+}$ ions to the C-domain is slow, binding the second $\mathrm{Ca}^{2}+$ to site III is rate-limiting ${ }^{6}$ but locks both $\mathrm{Ca}^{2+}$ in place. The slow kinetics of $\mathrm{Ca}^{2+}$ binding to site III may be due to an intra loop network of hydrogen bonds that surround the carboxyl group of Asp93 at position 1 in $\mathrm{Ca}^{2+}$ binding loop III, which must rearrange to allow the side chain of Asp93 to coordinate $\mathrm{Ca}^{2+}$. Association of the acidic sequence with $\mathrm{Ca}^{2+}$ binding site III places it in logical position to enhance the rate-limiting association of $\mathrm{Ca}^{2+}$ with the $\mathrm{C}$-domain. However, there are no structural features of $\mathrm{Ca}^{2}+$ binding loop III in the PEP-19:apo C-CaM complex that would clearly account for the increased rate of $\mathrm{Ca}^{2+}$ association. In particular, the intra loop hydrogen bonds persist in the PEP-19:apo C-CaM complex, since side chain oxygens of Asp93 are within 2-3 from backbone amides of residues 94-99. Instead, we hypothesize that the primary mechanism for increasing the rate of $\mathrm{Ca}^{2}+$ association involves increasing the negative ESP to steer $\mathrm{Ca}^{2}+$ to site III.

As described in the results section, acidic residues derived from $\mathrm{C}-\mathrm{CaM}$ and PEP-19 generate a large surface with significant negative ESP. Figure 7 shows that the topology of this surface includes a channel formed between the side chains of Glu84 and Glu87 in C-CaM and Glu38 in PEP-19. The channel leads to a basin that resembles a catcher's mitt that is surrounded by Asp31, Asp33 and Glu38 from PEP-19, and Asp93 and Asp95 from $\mathrm{C}$-CaM. This region of negative ESP could stabilize an initial encounter complex between $\mathrm{Ca}^{2+}$ and the PEP-19:apo C-CaM complex and allow transient two-dimensional diffusion of $\mathrm{Ca}^{2+}$ that is guided by the channel and basin surface topology and electrostatic gradients. An additional important feature is the location of Asp93, which is the first ligand for $\mathrm{Ca}^{2}+$ in loop III. Figure 7 shows that the backbone oxygen and beta protons of Asp93 contribute to formation of the negatively charged basin. As illustrated by the green arrows in Fig. 7, we propose that electrostatic gradients and surface topology funnel or steer $\mathrm{Ca}^{2+}$ to Asp93, and that this helps overcome the energy barrier

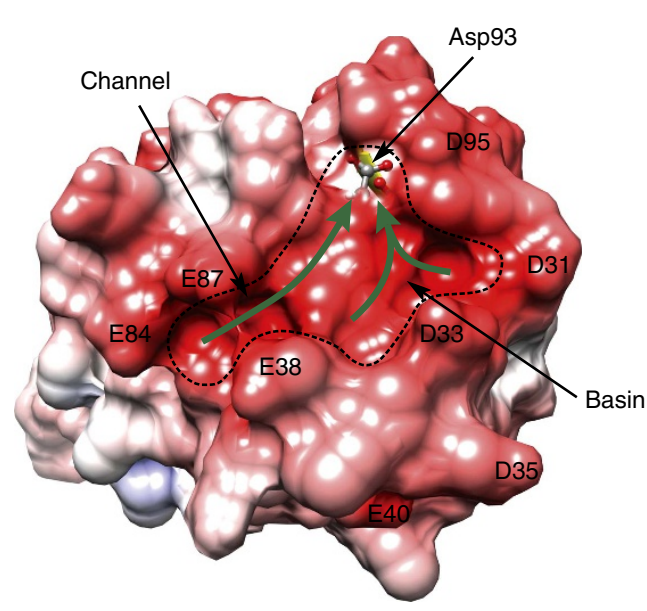

Figure 7 | Steering of $\mathrm{Ca}^{2+}$ to Asp93 in $\mathrm{Ca}^{2}+$ binding loop III. The topological features (channel and basin) near $\mathrm{Ca}^{2+}$ binding site III in the PEP-19:apo C-CaM complex are outlined by the dashed line. The surface contributed by Asp93 in C-CaM is shown as transparent, and is located in negatively charged basin. The green arrows illustrate funneling of $\mathrm{Ca}^{2+}$ to Asp93 guided by electrostatic steering and surface topology. presented by the intra loop hydrogen bonding network involving Asp93, thereby increasing the rate of $\mathrm{Ca}^{2}+$ binding and transition to the $\mathrm{Ca}^{2+}$ bound form. Similar electrostatic steering to Asp93 and Glu104 may be supported by the negative ESP shown in Supplementary Fig. 5.

It is well established that electrostatic interactions can increase the rate of protein-protein and protein-ligand association by orders of magnitude ${ }^{27,28}$. A specific role for ESP in modulating the kinetics of $\mathrm{Ca}^{2+}$ binding to CaM by PEP-19 is supported by several observations, including our mutation analysis ${ }^{17}$. Mutation of Asp31 or Asp33 to Ala, or Pro37 to Gly all significantly inhibit the ability of PEP-19 to modulate $\mathrm{Ca}^{2+}$ binding, but mutation of Asp35 has little effect. This is consistent with Fig. 7, which shows that Asp31 and Asp33 surround the negatively charged basin, while Aps35 extends away from site III. Mutation of Pro37 to Gly has the greatest effect on the ability of PEP-19 because it destabilizes the interaction between the acidic sequence and site III of CaM, thereby affecting the relative position of multiple acidic residues. A causal relationship between negative ESP and fast $\mathrm{Ca}^{2+} k_{\text {on }}$ rates is also supported by EFhands I, II and IV, which all have fast rates of $\mathrm{Ca}^{2+}$ association ${ }^{7-}$ 9 , and all have extensive negatively charged ESP near the respective loops as shown in Supplementary Fig. 6. Finally, Martin et l. $^{29}$ showed that acidic residues greatly affect the rate of $\mathrm{Ca}^{2+}$ association with EF-hand motifs even though they do not directly participate in $\mathrm{Ca}^{2}+$ binding. In this case, neutralization of acidic residues in the first EF-hand $\mathrm{Ca}^{2+}$ binding site of calbindin $9 \mathrm{~K}$ decreased the $\mathrm{Ca}^{2}+k_{\text {on }}$ by 45 -fold. We propose that PEP-19 achieves the inverse by adding negative charge to increase the rate of $\mathrm{Ca}^{2+}$ association.

It is well known that the $\mathrm{Ca}^{2+}$ binding affinity of $\mathrm{CaM}$ can be drastically increased on binding to $\mathrm{Ca}^{2+}$-dependent target peptides and proteins due to stabilizing the $\mathrm{Ca}^{2+}$-bound form and decreasing the rate of $\mathrm{Ca}^{2}+$ dissociation ${ }^{7,30,31}$. The data presented here provide an additional molecular mechanism to modulate $\mathrm{Ca}^{2+}$ binding to CaM that may be shared by other proteins. Neurogranin $(\mathrm{Ng})$, for example, is a small IQ motif protein that also binds to $\mathrm{CaM}$ in the presence or absence of $\mathrm{Ca}^{2+}$, and has an acidic sequence near its IQ motif. We showed that $\mathrm{Ng}$ increases the rate of $\mathrm{Ca}^{2+}$ dissociation from the C-domain of CaM to a similar extent as PEP-19, but has a lesser effect on the rate of $\mathrm{Ca}^{2+}$ association ${ }^{32}$. Thus, $\mathrm{Ng}$ decreases the affinity of $\mathrm{Ca}^{2}+$ binding to the $\mathrm{C}$-domain of CaM. Figure 8 compares acidic sequences that extend $\mathrm{N}$-terminal from the IQ dipeptide of PEP-19 and Ng. Positions corresponding to Phe30, Ile32 and Met34 in PEP-19, which anchor the acidic sequence to $\mathrm{Ca}^{2}+$ binding site III in CaM, are also hydrophobic residues in $\mathrm{Ng}$. On the basis of this, we predict that the global structure of the Ng:apo C-CaM complex will be very similar to the PEP-19:apo $\mathrm{C}-\mathrm{CaM}$ complex. However, the distribution of acidic residues in $\mathrm{Ng}$ and PEP-19 are different, which we predict confers different $\mathrm{Ca}^{2+}$ tuning properties. Another potential use of the acid/IQ

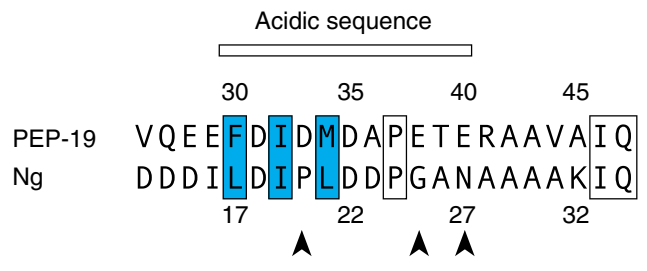

Figure 8 | Comparison of acidic sequences in PEP-19 and Ng. Blue boxes indicate residues that anchor the acidic sequence of PEP-19 to $\mathrm{Ca}^{2+}$ binding site III. Arrowheads indicate the position of acidic residues in the acidic sequences of PEP-19 and $\mathrm{Ng}$. 
motif is not as free regulator of CaM signalling, but as a module within the context of a larger $\mathrm{Ca}^{2}{ }_{+}$-dependent $\mathrm{CaM}$ target protein. In this scenario, the acidic/IQ motif would provide a docking site for apo $\mathrm{CaM}$ to modulate overall $\mathrm{Ca}^{2+}$-sensitivity, and allow CaM to reversibly transition to an adjacent $\mathrm{Ca}^{2+}$-dependent site to regulate protein activation/inactivation in response to specific $\mathrm{Ca}^{2}+$ signals.

In summary, the structure reported here shows a novel mode of interaction between apo $\mathrm{CaM}$ and a regulator of $\mathrm{CaM}$ signalling, and provides a molecular mechanism for modulation of $\mathrm{Ca}^{2+}$ binding to $\mathrm{CaM}$ that may be shared by other proteins. From a broader perspective, the high content of polar and charged residues in intrinsically disordered proteins makes them well suited to modulate ligand binding by changing the surface topology and electrostatic potential on binding to target proteins.

\section{Methods}

Expression and purification. Recombinant C-CaM and PEP-19 were expressed in bacteria and purified as described previously ${ }^{9}$. QuickChange II XL Site-directed

Mutagenesis Kit (Agilent Technologies) was used to generate PEP-19 mutant proteins.

cDNAs encoding mammalian C-CaM or human PEP-19 were synthesized with optimal bacterial codon usage (DNA2.0), and sub cloned into a pET23d expression vector. Isotopically labeled C-CaM or PEP-19 were prepared by expression in $E$. coli BL21(DE3) or BL21(DE3)pLysS using M9 minimal media supplemented with $1 \mathrm{gl}^{-115} \mathrm{NH}_{4} \mathrm{Cl}$ as sole nitrogen and $2 \mathrm{gl}^{-1}$ of unlabeled glucose or uniformly labeled ${ }^{13} \mathrm{C}$-glucose as carbon source.

After induction of C-CaM expression with IPTG, bacterial cells were collected by centrifugation, suspended in lysis buffer ( $25 \mathrm{mM}$ Tris, $1 \mathrm{mM}$ EDTA, pH 7.5), and then frozen. Frozen cell suspensions were thawed, sonicated and then centrifuged to yield a soluble fraction. Soluble protein was loaded on as semi preparative DEAE 5PW column (Waters) and eluted with a linear $0-300 \mathrm{mM} \mathrm{KCl}$ gradient. Ammonium sulfate $\left(\left(\mathrm{NH}_{4}\right)_{2} \mathrm{SO}_{4}\right)$ was slowly added to pooled fractions from the DEAE column to a final concentration of $2 \mathrm{M}$. After centrifugation to remove precipitated protein, the soluble protein fraction was loaded onto a phenyl sepharose column (GE Healthcare) and washed with loading buffer ( $25 \mathrm{mM}$ Tris, $2 \mathrm{mM}\left(\mathrm{NH}_{4}\right)_{2} \mathrm{SO}_{4}, 1 \mathrm{mM}$ EDTA, $\mathrm{pH}$ 7.5). Fractions containing $\mathrm{C}$-CaM were eluted with a linear 2-0 $\mathrm{mM}\left(\mathrm{NH}_{4}\right)_{2} \mathrm{SO}_{4}$ gradient, then pooled, dialyzed against the $20 \mathrm{mM}\left(\mathrm{NH}_{4}\right) \mathrm{HCO}_{3}, \mathrm{pH} 7.5$ for $24 \mathrm{~h}$ and lyophilized.

PEP-19 was expressed, and a soluble protein fraction prepared as described for $\mathrm{C}$-CaM above, except that the lysis buffer was $20 \mathrm{mM}$ MES, pH 6.5. The soluble protein fraction was passed through a Macro Q anion exchange column (Bio-Rad), which binds the majority of proteins, but not PEP-19. The $\mathrm{pH}$ of the fall-through from this first column was adjusted to $\mathrm{pH} 6$ and loaded on a Hi-Trap SP cation exchange column (GE Healthcare), and eluted with a linear $0-500 \mathrm{mM} \mathrm{KCl}$ gradient. Fractions containing PEP-19 were loaded on a Vydac C-4 column and eluted with a $0-60 \%$ acetonitrile, $0.1 \%$ TFA. Fractions containing PEP-19 were pooled and lyophilized.

Protein concentrations were estimated using an extinction coefficient of $\epsilon$ $276 \mathrm{~nm}=0.18 \mathrm{ml}^{-1} \mathrm{mg}^{-1}$ for C-CaM and $€ 215 \mathrm{~nm}=0.59 \mathrm{ml}^{-1} \mathrm{mg}^{-1}$ for PEP-19, or by using the BCA protein assay (Pierce).

NMR methodology. The NMR samples for structure determination contained either $0.8 \mathrm{mM}{ }^{13} \mathrm{C},{ }^{15} \mathrm{~N}$ C-CaM with excess unlabelled PEP-19 or ${ }^{13} \mathrm{C},{ }^{15} \mathrm{~N}$ PEP-19 with excess unlabelled C-CaM. All NMR samples contained in $10 \mathrm{mM}$ imidazole-d4 (pH 6.3), $100 \mathrm{mM} \mathrm{KCl,} 5 \mathrm{mM}$ EDTA-d16 and $10 \mu \mathrm{M}$ 2,2-dimethyl-2silapentane-5-sulfonate (DSS), $95 \% \mathrm{H}_{2} \mathrm{O} / 5 \% \mathrm{D}_{2} \mathrm{O}$ or $99.99 \% \mathrm{D}_{2} \mathrm{O}$. The sample used for RDC measurements also contained $5.0 \% \mathrm{C} 12 \mathrm{E} 5$ poly-ethylene-glycol/hexanol mixture. NMR data were acquired on a Bruker $600 \mathrm{MHz}$ spectrometer equipped with a 5-mm TXI cyroprobe at $298 \mathrm{~K}$

Backbone assignments for bound PEP-19 were made using ${ }^{15} \mathrm{~N}$ HSQC, HNCA, $\mathrm{HN}(\mathrm{CO}) \mathrm{CA}, \mathrm{HNCACB}, \mathrm{CBCA}(\mathrm{CO}) \mathrm{NH}, \mathrm{HNCO}$ and ${ }^{15} \mathrm{~N}$-edited NOESY-HSQC experiments. Backbone assignments for bound apo $\mathrm{C}$-CaM were obtained from published data ${ }^{17}$. Amides of Asp131 and Gly134 in apo C-CaM could not be observed due to conformational exchange on the $\mu$ s to ms timescale on PEP-19 binding ${ }^{17}$. Aliphatic side chain assignments were made using $2 \mathrm{D}{ }^{1} \mathrm{H}-{ }^{13} \mathrm{C}$ HSQC, 3D HN(CO)HBHA, (H)CC(CO)NH, H(CCCO)NH, CCH-TOCSY, HCCHTOCSY and $\mathrm{HCCH}-\mathrm{COSY} .{ }^{1} \mathrm{H}$ aromatic side chain assignments were obtained using $2 \mathrm{D}(\mathrm{HB}) \mathrm{CB}(\mathrm{CGCD}) \mathrm{HD}$ and $(\mathrm{HB}) \mathrm{CB}(\mathrm{CGCE}) \mathrm{HE}$. Intramolecular NOEs were assigned by $3 \mathrm{D}^{15} \mathrm{~N}$ NOESY-HSQC and ${ }^{13} \mathrm{C}$ NOESY-HSQC. To reduce ambiguous intermolecular NOEs, 3D F $1^{-1}{ }^{13} \mathrm{C} /{ }^{15} \mathrm{~N}$-filtered, $\mathrm{F}_{3^{-}}{ }^{13} \mathrm{C}$-edited NOESY spectra were acquired by using ${ }^{13} \mathrm{C},{ }^{15} \mathrm{~N}$ C-CaM bound to unlabelled PEP-19 as well as ${ }^{13} \mathrm{C},{ }^{15} \mathrm{~N}$ PEP-19 bound to unlabelled C-CaM. The mixing time for all NOESY experiments was $100 \mathrm{~ms}$. H-N RDC measurements were performed using in-phase/anti-phase ${ }^{1} \mathrm{H},{ }^{15} \mathrm{~N}$ HSQC experiment ${ }^{33}$.
Heteronuclear ${ }^{15} \mathrm{~N}\left\{{ }^{1} \mathrm{H}\right\}$ NOEs were collected at $298 \mathrm{~K}$ at a ${ }^{15} \mathrm{~N}$ frequency of $60 \mathrm{MHz}$. The NMR samples included $0.5 \mathrm{mM}{ }^{15} \mathrm{~N}$-labelled PEP-19, or PEP(P37G) with $1 \mathrm{mM}$ unlabelled apo C-CaM. NOE values were measured from spectra with and without proton saturation recorded in an interleaved manner. Proton saturation was acquired using a $120^{\circ}{ }^{1} \mathrm{H}$ pulse applied every $5 \mathrm{~s}$. In the case of the NONOE spectra, a net relaxation delay of $5 \mathrm{~s}$ was employed, while a relaxation delay of $2 \mathrm{~s}$ before a $3 \mathrm{~s}$ proton presaturation period was employed for the NOE spectra. Heteronuclear ${ }^{15} \mathrm{~N}\left\{{ }^{1} \mathrm{H}\right\}$ NOE values were determined by measuring the ratio of peak intensities in spectra acquired with and without proton saturation. The uncertainty for NOE values was evaluated using the standard deviation of the noise in empty spectral regions of the spectra ${ }^{34}$.

All NMR spectra were processed and analyzed using Topspin2.0 (Bruker) and FELIX 2004 (MSI, San Diego, CA, USA). ${ }^{1} \mathrm{H}$ chemical shifts were referenced to DSS, and ${ }^{15} \mathrm{~N}$ and ${ }^{13} \mathrm{C}$ chemical shifts were referenced indirectly using their respective gyromagnetic ratios ${ }^{35}$. The average amide chemical shift change was calculated using the following equation:

$$
\Delta \delta_{\mathrm{avg}}=\sqrt{\frac{(\Delta \delta \mathrm{H})^{2}+(\Delta \delta \mathrm{N} / 5)^{2}}{2}}
$$

Structure calculations. Initial structures of the complex were generated using a torsion-angle molecular dynamics protocol with CNS 1.3 (refs 36,37) using NOE distance restraints, hydrogen bond distance restraints predicted based on the secondary structure derived from the $\mathrm{CSI}^{38}$, and dihedral restraints predicted by TALOS $^{39}$. Further structure refinement with the addition of backbone H-N RDC restraints was performed by XPLOR-NIH (version 2.42$)^{40}$. Initial estimation for the axial component of the molecular alignment tensor (Da) and rhombicity $(R)$ were obtained from the lowest energy structure calculated by CNS using PALES ${ }^{41}$. A family of 300 structures was generated, and the final ensemble of 20 structures with lowest energies was selected for analysis. Structural analysis and statistics were obtained using MOLMOL ${ }^{42}$ and PROCHECK-NMR ${ }^{43}$. PROCHECK-NMR shows $90.1 \%$ of residues in the most favored and $6.9 \%$ in additional allowed regions for the residues Ser81-Thr146 in C-CaM and Phe30-Ala58 in PEP-19, with 1.7 and $1.2 \%$ of residues in the generously allowed and disallowed regions, respectively.

Graphics and analyses were performed with PyMOL (DeLano, W.L (2002) the PyMOL Molecular Graphics System, DeLano Scientific, Palo Alto, CA, USA) and the UCSF Chimera package (Chimera is developed by the Resource for Biocomputing, Visualization and Informatics at the University of California, San Francisco (supported by NIGMS P41-GM103311). Accessible surface area was calculated with NACCESS (Hubbard, S.J. and Thornton J.M. (1993)) using a probe radius of $1.40 \AA$. Poisson Boltzman ESP was calculated using APBS and PDB2PQC online web server (http://www.poissonboltzmann.org).

Paramagnetic relaxation enhancement. Aspartate 31 was converted to Cys in both PEP-19 and PEP(P37G) for site-directed spin labelling with 3-(2-iodoacetamido)-2,2,5,5-tetramethyl-1-pyrrolidinyloxy (PROXYL; Sigma). A ten-fold molar excess of PROXYL dissolved in ethanol was added to Cys derivatives in $40 \mathrm{mM}$ Tris (pH 8), 2 mM EDTA and $6 \mathrm{M}$ urea, and incubated at room temperature in the dark for $4 \mathrm{~h}$. Unreacted PROXYL was then quenched with $10 \mathrm{mM}$ 2-mercaptoethanol and removed by desalting using a Bio-Rad P2 column. Chemical shifts of amide resonances in ${ }^{15} \mathrm{~N}$-labelled apo C-CaM bound to spin-labelled PEP-19 (PEP-19SL) or PEP(P37G) (PEP(P37G)SL) are almost identical to those observed when bound to PEP-19 or PEP(P37G), which indicates that the introduction of the PROXYL group does not greatly perturb structure. HSQC spectra were collected at $298 \mathrm{~K}$ in the absence and presence of 5 molar equivalents of sodium ascorbate to reduce PROXYL to its diamagnetic form. After linear prediction and zero filling, the spectra were fitted using Lorentzian function in each dimension. The PRE effect was measured as a normalized ratio $\left(I_{\mathrm{ox}} / I_{\text {red }}\right)$ of signal intensities in the oxidized (paramagnetic) and reduced (diamagnetic) state.

Data availability. All relevant data are available from the authors. The assigned chemical shift values, constraints and the atomic coordinates of the final ensemble of 20 structures have been deposited in the Biological Magnetic Resonance Data Bank under accession code 25796 and Protein Data Bank under accession code 2 N77.

\section{References}

1. Persechini, A. \& Kretsinger, R. H. The central helix of calmodulin functions as a flexible tether. J. Biol. Chem. 263, 12175-12178 (1988).

2. Crivici, A. \& Ikura, M. Molecular and structural basis of target recognition by calmodulin. Annu. Rev. Biophys. Biomol. Struct. 24, 85-116 (1995).

3. Yamniuk, A. P. \& Vogel, H. J. Calmodulin's flexibility allows for promiscuity in its interactions with target proteins and peptides. Mol. Biotechnol. 27, 33-57 (2004).

4. Linse, S., Helmersson, A. \& Forsén, S. Calcium binding to calmodulin and its globular domains. J. Biol. Chem. 266, 8050-8054 (1991).

5. Bayley, P. M., Findlay, W. A. \& Martin, S. R. Target recognition by calmodulin: Dissecting the kinetics and affinity of interaction using short peptide sequences. Protein Sci. 5, 1215-1228 (1996). 
6. Putkey, J. A. et al. Acidic/IQ motif regulators of calmodulin. J. Biol. Chem. 283, 1401-1410 (2008).

7. Johnson, J. D., Snyder, C., Walsh, C. \& Flynn, M. Effects of myosin light chain kinase and peptides on $\mathrm{Ca} 2+$ exchange with the $\mathrm{N}$ - and $\mathrm{C}$-temrinal $\mathrm{Ca} 2+$ binding sites of calmodulin. J. Biol. Chem. 271, 761-767 (1996).

8. Persechini, A., White, H. D. \& Gansz, K. J. Different mechanisms for $\mathrm{Ca} 2+$ dissociation from complexes of calmodulin with nitric oxide synthase or myosin light chain kinase. J. Biol. Chem. 271, 62-67 (1996).

9. Putkey, J. A., Kleerekoper, Q., Gaertner, T. R. \& Waxham, M. N. A new role for IQ motif proteins in regulating calmodulin function. J. Biol. Chem. 278, 49667-49670 (2003).

10. Ziai, M. R., Sangameswaran, L., Hempstead, J. L., Danho, W. \& Morgan, J. I. An immunochemical analysis of the distribution of a brain-specific polypeptide, PEP-19. J. Neurochem. 51, 1771-1776 (1988).

11. Wei, P., Blundon, J. A., Rong, Y., Zakharenko, S. S. \& Morgan, J. I. Impaired locomotor learning and altered cerebellar synaptic plasticity in pep-19/PCP4null mice. Mol. Cell. Biol. 31, 2838-2844 (2011).

12. Kim, E. E. et al. PCP4 regulates Purkinje cell excitability and cardiac rhythmicity. J. Clin. Invest. 124, 5027-5036 (2014).

13. Harashima, S., Wang, Y., Horiuchi, T., Seino, Y. \& Inagaki, N. Purkinje cell protein 4 positively regulates neurite outgrowth and neurotransmitter release. J. Neurosci. Res. 89, 1519-1530 (2011).

14. Mouton-Liger, F. et al. PCP4 (PEP19) overexpression induces premature neuronal differentiation associated with $\mathrm{Ca}(2+)$ /calmodulin-dependent kinase II-delta activation in mouse models of down syndrome. J. Comp. Neurol. 519, 2779-2802 (2011).

15. Erhardt, J. A., Legos, J. J., Johanson, R. A., Slemmon, J. R. \& Wang, X Expression of PEP-19 inhibits apoptosis in PC12 cells. Neuroreport 11, 3719-3723 (2000)

16. Kanazawa, Y. et al. Degradation of PEP-19 calmodulin-binding protein by calpain is implicated in neuronal cell death induced by intracellular Ca2 + overload. Neuroscience 154, 473-481 (2008).

17. Wang, X., Xiong, L. W., El Ayadi, A., Boehning, D. \& Putkey, J. A. The calmodulin regulator protein, PEP-19, sensitizes ATP-induced Ca2 + release. J. Biol. Chem. 288, 2040-2048 (2013).

18. Kleerekoper, Q. \& Putkey, J. A. PEP-19: an instrinsically disordered regulator of CaM signaling. J. Biol. Chem. 284, 7455-7464 (2009).

19. Wang, X., Kleerekoper, Q. K., Xiong, L. W. \& Putkey, J. A. Intrinsically disordered PEP-19 confers unique dynamic properties to apo and calcium calmodulin. Biochemistry 49, 10287-10297 (2010).

20. Wang, C., Chung, B. C., Yan, H., Lee, S. Y. \& Pitt, G. S. Crystal structure of the ternary complex of a $\mathrm{NaV} \mathrm{C}$-terminal domain, a fibroblast growth factor homologous factor, and calmodulin. Structure 20, 1167-1176 (2012).

21. Houdusse, A. et al. Crystal structure of apo-calmodulin bound to the first two IQ motifs of myosin V reveals essential recognition features. Proc. Natl Acad. Sci. USA 103, 19326-19331 (2006)

22. Chagot, B. \& Chazin, W. J. Solution NMR structure of Apo-calmodulin in complex with the IQ motif of human cardiac sodium channel NaV1.5. J. Mol. Biol. 406, 106-119 (2011).

23. Slemmon, J. R. et al. Camstatins are peptide antagonists of calmodulin based upon a conserved structural motif in PEP-19, neuroganin, and neuromodulin. J. Biol. Chem. 271, 15911-15917 (1996).

24. Battiste, J. L. \& Wagner, G. Utilization of site-directed spin labeling and highresolution heteronuclear nuclear magnetic resonance for global fold determination of large proteins with limited nuclear overhauser effect data. Biochemistry 39, 5355-5365 (2000).

25. Tompa, P. \& Fuxreiter, M. Fuzzy complexes: polymorphism and structural disorder in protein-protein interactions. Trends Biochem. Sci. 33, 2-8 (2008).

26. Malmendal, A., Evenas, J., Forsen, S. \& Akke, M. Structural dynamics in the C-terminal domain of calmodulin at low calcium levels. J. Mol. Biol. 293, 883-899 (1999)

27. McCammon, J. A. Darwinian biophysics: electrostatics and evolution in the kinetics of molecular binding. Proc. Natl Acad. Sci. USA 106, 7683-7684 (2009).

28. Schreiber, G., Haran, G. \& Zhou, H. X. Fundamental aspects of protein-protein association kinetics. Chem. Rev. 109, 839-860 (2009).

29. Martin, S. R., Linse, S., Johansson, C., Bayley, P. M. \& Forsén, S. Protein surface charges and $\mathrm{Ca} 2+$ binding to individual sites in calbindin D9k: stopped-flow studies. Biochemistry 29, 4188-4193 (1990).

30. Olwin, B. B. \& Storm, D. R. Calcium binding to complexes of calmodulin and calmodulin binding proteins. Biochemistry 24, 8081-8086 (1985).

31. Peersen, O. B., Madsen, T. S. \& Falke, J. J. Intermolecular tuning of calmodulin by target peptides and proteins: differential effects on
$\mathrm{Ca} 2+$ binding and implications for kinase activation. Protein Sci. 6, 794-807 (1997).

32. Gaertner, T. R., Putkey, J. A. \& Waxham, M. N. RC3/neurogranin and $\mathrm{C} 2+$ /calmodulin-dependent protein kinase II produce opposing effects on the affinity of calmodulin for calcium. J. Biol. Chem. 279, 39374-39382 (2004).

33. Ottiger, M., Delaglio, F. \& Bax, A. Measurement of J and dipolar couplings from simplified two-dimensional NMR spectra. J. Magn. Reson. 131, 373-378 (1998).

34. Farrow, N. A. et al. Backbone dynamics of a free and phosphopeptidecomplexed Src homology 2 domain studied by $15 \mathrm{~N}$ NMR relaxation. Biochemistry 33, 5984-6003 (1994)

35. Wishart, D. S. et al. H-1, C-13 and N-15 chemical-shift referencing in biomolecular NMR. J. Biomol. NMR 6, 135-140 (1995).

36. Brunger, A. T. et al. Crystallography \& NMR system: a new software suite for macromolecular structure determination. Acta Crystallogr. D Biol. Crystallogr. 54, 905-921 (1998)

37. Brunger, A. T. Version 1.2 of the crystallography and NMR system. Nat. Protoc 2, 2728-2733 (2007).

38. Wishart, D. S. \& Sykes, B. D. The 13C chemical shift index: a simple method for the identification of protein secondary structure using 13C chemical-shift data. J. Biomol. NMR 4, 171-180 (1994).

39. Cornilescu, G., Delaglio, F. \& Bax, A. Protein backbone angle restraints from searching a database for chemical shift and sequence homology. J. Biomol. NMR 13, 289-302 (1999).

40. Schwieters, C. D., Kuszewski, J. J. \& Clore, G. M. Using Xplor-NIH for NMR molecular structure determination. Prog. NMR Spectrosc. 48, 47-62 (2006).

41. Zweckstetter, M. \& Bax, A. Prediction of sterically induced alignment in a dilute liquid crystalline phase: aid to protein structure determination by NMR. J. Am. Chem. Soc 122, 3791-3792 (2000).

42. Koradi, R., Billeter, M. \& Wuthrich, K. MOLMOL: a program for display and analysis of macromolecular structures. J. Mol. Graph. 14, 51-55 (1996).

43. Laskowski, R. A., Rullmannn, J. A., MacArthur, M. W., Kaptein, R. \& Thornton, J. M. AQUA and PROCHECK-NMR: programs for checking the quality of protein structures solved by NMR. J. Biomol. NMR 8, 477-486 (1996).

\section{Acknowledgements}

The work was supported in part by grant R01GM104290 from the National Institutes of Health to J.A.P.

\section{Author contributions}

X.W. produced NMR samples, performed NMR experiments and determined the NMR solution structure. J.A.P. designed and supervised the project. Both J.A.P and X.W. interpreted the results and wrote the manuscript.

\section{Additional information}

Supplementary Information accompanies this paper at http://www.nature.com/ naturecommunications

Competing financial interests: The authors declare no competing financial interests

Reprints and permission information is available online at http://npg.nature.com/ reprintsandpermissions/

How to cite this article: Wang, X. \& Putkey, J. A. PEP-19 modulates calcium binding to calmodulin by electrostatic steering. Nat. Commun. 7, 13583 doi: 10.1038/ncomms13583 (2016).

Publisher's note: Springer Nature remains neutral with regard to jurisdictional claims in published maps and institutional affiliations.

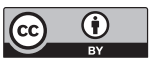

This work is licensed under a Creative Commons Attribution 4.0 International License. The images or other third party material in this article are included in the article's Creative Commons license, unless indicated otherwise in the credit line; if the material is not included under the Creative Commons license, users will need to obtain permission from the license holder to reproduce the material. To view a copy of this license, visit http://creativecommons.org/licenses/by/4.0/

C) The Author(s) 2016 